\title{
Radiofrequency Ablation Versus Bipolar Electrocautery for the Treatment of Nasal Obstruction in Obstructive Sleep Apnea Patients Using Continuous Positive Airway Pressure
}

Krongthong Tawaranurak, M.D. ${ }^{1}$, Wiralpat Sartyoungkul, M.D. ${ }^{1}$, Janya Wongkittihawon, B.N.S. ${ }^{2}$

${ }^{1}$ Department of Otolaryngology Head and Neck Surgery, Faculty of Medicine, Prince of Songkla University, Hat Yai, Songkhla 90110, Thailand.

${ }^{2}$ Nursing Department, Faculty of Medicine, Prince of Songkla University, Hat Yai, Songkhla 90110, Thailand.

Received 14 February 2020 • Revised 13 April 2020 • Accepted 30 April $2020 \bullet$ Published online 1 July 2020

\section{Abstract:}

Objective: To investigate the treatment effect of radiofrequency ablation (RFA) on nasal obstruction, continuous positive airway pressure (CPAP) compliance, Epworth sleepiness scale (ESS) and sleep quality were compared with that of bipolar electrocautery (BEC) in patients using CPAP.

Material and Methods: Participants were randomised into two groups and treated with either RFA or BEC. Data were collected regarding nasal obstruction, total nasal symptoms, CPAP compliance, daytime sleepiness and sleep quality before and after treatment at 1,3 and 6 months.

Results: Twenty-eight patients were enrolled in the study. Both methods relieved nasal obstruction at 1,3 and 6 months. At 6 months, the symptom was improved by $83.4 \%$ and $64.2 \%$ in the RFA and BEC groups, respectively. The total nasal symptoms decreased at 3 and 6 months in both groups as well, exhibiting $75.7 \%$ and $40.6 \%$ improvement at 6 months in the RFA and BEC groups, respectively.

Conclusion: Both RFA and BEC have the ability to relieve nasal obstruction in such patients.

Keywords: bipolar electrocautery, CPAP, nasal obstruction, obstructive sleep apnoea, radiofrequency ablation

Contact: Krongthong Tawaranurak, M.D.

Department of Otolaryngology Head and Neck Surgery, Faculty of Medicine,

Prince of Songkla University, Hat Yai, Songkhla 90110, Thailand.

E-mail: golf_psu@hotmail.com

This is an open access article under the CC BY-NC-ND license

(http://www.jhsmr.org/index.php/jhsmr/about/editorialPolicies\#openAccessPolicy).

J Health Sci Med Res 2020;38(4):297-305 doi: $10.31584 /$ jhsmr.2020749 www.jhsmr.org 


\section{Introduction}

Obstructive sleep apnoea (OSA) is a sleep disorder that leads to sleep disturbance and excessive daytime sleepiness. ${ }^{1,2}$ It also affects patients' work and quality of life and increases the risk of cardiovascular consequences. ${ }^{3-7}$ Continuous positive airway pressure (CPAP) is the primary treatment for moderate to severe OSA. ${ }^{8,9}$ Nasal obstruction is one of the most common symptoms complained about during CPAP use and is usually caused by hypertrophy of the inferior turbinate. ${ }^{10-12}$ This side effect often causes patient discomfort when using CPAP, leading to poor compliance and, eventually, abandonment of the therapy. ${ }^{13-15}$ Conservative medical therapies, such as nasal steroids and decongestants, are not always effective in controlling turbinate hypertrophy in these patients. ${ }^{16-18}$ Recently, a systemic review and meta-analytic study did not confirm the benefits of topical nasal steroid on CPAP compliance in OSA patients. ${ }^{19}$ Therefore, surgical treatments for turbinate tissue shrinkage should be considered in such patients with medical failure. ${ }^{20-22}$ Among these surgical methods, the minimally invasive procedures, including electrocautery and radiofrequency ablation (RFA), are preferred because they reduce tissue volume while preserving mucosal epithelial function, causing minimal complications. ${ }^{23}$ Thus, this study was designed to investigate the treatment effect of RFA on nasal congestion compared with that of bipolar electrocautery (BEC) in patients using CPAP. Furthermore, we assessed the impact of total nasal symptoms, peak nasal inspiratory flow (PNIF), CPAP compliance, CPAP attitude, postoperative pain score and sleep quality after treatment.

\section{Material and Methods}

A prospective, randomised, single-blind study was performed at the snoring clinic of Otolaryngology Outpatient Department and the operating room of Songklanagarind
Hospital from January 2016 to May 2019. The study protocol was approved by the Human Research Ethics Committee, Faculty of Medicine, Prince of Songkla University, and informed consent was obtained from each patient. Adult OSA patients using fixed pressure CPAP for at least 3 months who had symptoms of nasal obstruction via a visual analogue scale of $>5$ and bilateral inferior turbinate hypertrophy of grades 2-3 via the Friedman grading system ${ }^{23}$ were enrolled. Patients with previous nasal or sinus surgery, septal deformity, nasal polyposis, sinusitis, nasal cavity tumour or coagulation disorder were excluded. All patients stopped using nasal or systemic steroids for at least 2 weeks, and no decongestants or antihistamine were taken within 1 week before surgery.

The patients were randomly assigned into two groups (Groups A and B) by block of four randomisation. The RFA treatment was applied in Group A, and the BEC treatment was applied in Group B. An investigator prepared the setting machine behind the partition screen and patients were blinded to which type of energy was used. The same reusable bipolar tip (Bipolar RaVoR ${ }^{\mathrm{TM}}$ needle electrode, Sutter Medizintechnik GMBH, Freiburg, Germany) was used in both groups. The surgical procedure was performed by a single otolaryngologist (K.T.) who was unblinded to the treatment group. Another unblinded otolaryngologist (W.S.) examined all patients before and after treatment.

The procedures were performed in an operating room under local anaesthesia. A cotton pledget soaked in $4.0 \%$ xylocaine solution was placed into each inferior turbinate. After 5 minutes, under a nasal telescope, $1.0 \%$ lidocaine hydrochloride $40 \mathrm{mg} / 2 \mathrm{~mL}$ for $2 \mathrm{~mL}$ was infiltrated at the anterior end of the inferior turbinate. Then, the surgeon inserted the active portion of a bipolar needle electrode under visualisation into the submucosa of the anterior part of the inferior turbinate. The RFA was 
performed using a Quantum Molecular Resonance generator (Quantum; Telea Electronic Engineering, Sandrigo, Italy) with an energy of 4 megahertz. For the BEC, an energy of 20 watt was delivered by an Electrosurgical unit (ERBE ICC-350; Erbe Elektromedizin GmbH, Tübingen, Germany). Immediate nasal packing was applied postoperatively for both procedures. All patients were observed carefully for 30 minutes and allowed to be discharged with home medication, including oral antibiotics (Amoxicillin 2 gram/ day or Azithromycin $500 \mathrm{mg} /$ day for penicillin allergy) for 7 days, rescue medications for pain (acetaminophen) and oral decongestants (pseudoephedrine). Topical nasal steroid or antihistamine medication was not allowed during the study.

All patients were evaluated regarding their total nasal symptoms, endoscopic inferior turbinate grading, PNIF, CPAP compliance, Epworth sleepiness scale (ESS) and sleep quality measured by the Functional Outcomes of Sleep Questionnaire (FOSQ) preoperatively, at 1, 3 and 6 months after surgery. Moreover, the pain scores and surgical complications were assessed both immediately and 2 weeks after surgery. The nasal symptoms were assessed by using visual analogue scale (VAS), a $10-\mathrm{cm}$ scale that ranges from no symptoms to worst symptom for each of the symptoms including nasal obstruction, rhinorrhea, nasal itching, sneezing, sense of smell, cough, eye itching, postnasal drip and sinonasal pain. The total nasal symptom score was the sum of scores for all nasal symptoms. Inferior turbinate was graded by nasal endoscopy according to the Friedman grading system. ${ }^{24}$ Grade I was defined as mild enlargement without obvious obstruction. Grade II was in between grade I and III. For grade III, the turbinate completely occluded the nasal cavity. PNIF was used to assess the severity of nasal obstruction by measuring the volume of nasal airflow (L/ min) using the In-Check portable inspiratory flow meter (Clement Clarke International Ltd., Harlow, United Kingdom).
Patients were asked to exhale and then inhale through the nose three times and the maximum value among three values was chosen as the PNIF. CPAP compliance was measured by self-reported diary records of nightly CPAP use. Good CPAP compliance is usually defined as at least 4 hours of nightly use for $70.0 \%$ of the nights. ${ }^{8,9}$ The ESS is a set of self-reported questionnaires that measures the degree of daytime sleepiness in eight common situations. ${ }^{25}$ An ESS score greater than 10 is generally considered excessively sleepy. The sleep quality was measured by the Thai version of FOSQ. ${ }^{26}$ This is a set of selfadministered questionnaires consisted of 30 items focusing on five domains including general productivity, vigilance, social outcome, activity level, and sexual relationship. Each item is scored on a 4-point likert scale in which the lower score means more dysfunction of quality of life. The attitude and ease of CPAP use were measured by $10-\mathrm{cm}$ VAS scale ranging from easiest to most difficult. The total score can range from 0 to 24 in which a lower score means less sleepiness.

Statistical analysis was conducted using the EpiData software (version 3.1) and R software (version 3.5.1). The baseline data were reported as numbers (percentage), means (standard deviation) or medians (interquartile range). Comparison between the groups was performed via the chi-squared test or Fisher's exact test for nominal variables and the Wilcoxon-MannWhitney $U$ test for ordinal variables. The generalised estimating equation model was used to compare data within the same groups at before and 1, 3, 6 months after surgery. A p-value of less than 0.05 was considered statistically significant.

\section{Results}

All patients who entered the protocol $(n=28)$ completed the study. Subjects were divided into two groups of 14 patients each. The mean age was $52.8 \pm 9.7$ 
years in the RFA group and $51.9 \pm 12.2$ years in the BEC group. The average body mass index (BMI) was 28.9 \pm 3.8 $\mathrm{kg} / \mathrm{m}^{2}$ in the RFA group compared with $27.3 \pm 3.3 \mathrm{~kg} / \mathrm{m}^{2}$ in the BEC group. The severity of OSA and the characteristics of CPAP usage were not significantly different between the groups (Table 1). Moreover, the baseline nasal symptoms, PNIF, ESS and FOSQ were almost similar in both groups.

Nasal obstruction in both groups postoperatively decreased significantly at 1,3 and 6 months consecutively ( $p$-value<0.001). Additionally, there was no statistically significant difference between the two groups (Table 2). At 6 months post-surgery, nasal obstruction improved by $83.4 \%$ and $64.2 \%$ in the RFA and BEC groups, respectively. In the RFA group, there were higher baseline total nasal symptoms scores than in the BEC group. However, these scores reduced significantly after 1, 3 and
6 months in the RFA group ( $p$-value $<0.001, p$-value $<$ 0.001 , p-value $<0.001$ ) compared with after 3 and 6 months in the BEC group ( $p$-value $<0.05, p$-value $<0.05$ ), without a statistical difference between the groups (Table 2). There was an overall $75.7 \%$ and $40.6 \%$ improvement in the total nasal symptom scores in the RFA and BEC groups, respectively. The symptoms of rhinorrhoea, sneezing, coughing and itchy nose improved significantly at 1, 3 and 6 months postoperation in the RFA group. The symptoms of itchy eyes, anosmia and facial pain did not exhibit significant changes before or after treatment in either group.

The PNIF increased significantly at 1,3 and 6 months in the RFA group ( $p-$ value $=0.005, p-$ value $=$ $0.001, p-v a l u e=0.008$ ) compared with at 3 and 6 months in the BEC group ( $p$-value=0.022, $p$-value=0.002), without a significant difference between the groups. The inferior

Table 1 Demographic characteristics of participants $(n=28)$

\begin{tabular}{|c|c|c|c|}
\hline Characteristics & RFA $(n=14)$ & BEC $(n=14)$ & $p$-value \\
\hline Age (years), mean (S.D.) & $52.8(9.7)$ & $51.9(12.2)$ & 0.773 \\
\hline Gender, n (\%) & & & 0.385 \\
\hline Male & $9(64.3)$ & $12(85.7)$ & \\
\hline Female & $5(35.7)$ & $2(14.3)$ & \\
\hline BMI $\left(\mathrm{kg} / \mathrm{m}^{2}\right)$, mean (S.D.) & $28.9(3.8)$ & $27.3(3.3)$ & 0.232 \\
\hline Underlying disease, $\mathrm{n}(\%)$ & & & 1.000 \\
\hline Hypertension & $9(64.3)$ & $5(35.7)$ & \\
\hline Diabetes mellitus & $4(28.6)$ & $2(14.3)$ & \\
\hline Allergy & $7(50.0)$ & $4(28.6)$ & \\
\hline Dyslipidaemia & $6(42.9)$ & $6(42.9)$ & \\
\hline Severity of OSA (events/h), n (\%) & & & 0.695 \\
\hline Mild & $1(7.1)$ & $0(0)$ & \\
\hline Moderate & $5(35.7)$ & $4(28.6)$ & \\
\hline Severe & $4(28.6)$ & $10(71.4)$ & \\
\hline CPAP pressure $\left(\mathrm{cmH}_{2} \mathrm{O}\right)$, mean (S.D.) & $8.8(2.1)$ & $7.8(1.9)$ & 0.216 \\
\hline Inferior turbinate grading, $\mathrm{n}(\%)$ & & & 0.678 \\
\hline Grade 2 & $3(21.4)$ & $5(35.7)$ & \\
\hline Grade 3 & 11 (78.6) & 9 (64.3) & \\
\hline
\end{tabular}

$\mathrm{BMI}=$ body mass index, OSA=obstructive sleep apnoea, CPAP=continuous positive airway pressure, RFA=radiofrequency ablation, $\mathrm{BEC}=$ bipolar electrocautery, S.D.=standard deviation, $\mathrm{cmH}_{2} \mathrm{O}=$ centimetres of water, $\mathrm{kg} / \mathrm{m}^{2}=\mathrm{kilogram}$ per meter squared 
turbinate grading was reduced at 1, 3 and 6 months in both groups $(p-v a l u e<0.001)$. In the RFA group, the ESS scores decreased significantly at 1,3 and 6 months postoperation compared with at 6 months in the BEC group. However, the FOSQ did not change pre- or postoperatively in either group (Table 3).

Table 2 Comparison of the nasal obstruction and total nasal symptoms at baseline, 1, 3 and 6 months after treatment

\begin{tabular}{lllll}
\hline Symtoms & Pre-treatment & 1 month & 3 months & 6 months \\
\hline Nasal obstruction, mean (S.D.) & & & & \\
RFA & $6.5(1.5)$ & $2.2(1.0)^{\star *}$ & $1.4(0.9)^{\star \star}$ & $1.4(1.4)^{\star \star}$ \\
BEC & $5.9(1.0)$ & $2.5(2.3)^{\star \star}$ & $1.8(1.9)^{\star *}$ & $1.9(1.6)^{\star \star}$ \\
p-value & 0.231 & 0.586 & 0.565 & 0.348 \\
Total nasal symptoms, mean (S.D.) & & & \\
RFA & $35.4(15.3)$ & $14.8(11.1)^{\star \star}$ & $12.5(5.9)^{\star \star}$ & $11.7(12.3)^{\star \star}$ \\
BEC & $21.3(11.7)$ & $14.3(13.9)$ & $9.7(10.0)^{\star}$ & $9.7(9.0)^{\star}$ \\
P-value & 0.011 & 0.907 & 0.371 & 0.638 \\
\hline
\end{tabular}

${ }^{*} \mathrm{p}$-value (pre-post-treatment) $<0.05,{ }^{* *} \mathrm{p}$-value (pre-post-treatment) $<0.001$

S.D.=standard deviation, RFA=radiofrequency ablation, BEC=bipolar electrocautery

Table 3 Comparison of the peak nasal inspiratory flow, inferior turbinate grading, Epworth sleepiness scale and total functional outcome of sleep questionnaire at baseline, 1, 3 and 6 months after treatment

\begin{tabular}{|c|c|c|c|c|}
\hline Parameters & Pre-treatment & 1 month & 3 months & 6 months \\
\hline \multicolumn{5}{|c|}{ PNIF (L/min), mean (S.D.) } \\
\hline RFA & $101.6(34.0)$ & $131.9(25.6)^{*}$ & $142.1(29.9)^{*}$ & $142.1(31.2)^{*}$ \\
\hline BEC & $107.1(27.4)$ & $127.1(34.1)$ & $133.2(36.5)^{*}$ & $143.7(37.5)^{*}$ \\
\hline p-value & 0.641 & 0.678 & 0.485 & 0.905 \\
\hline \multicolumn{5}{|c|}{ Inferior turbinate grading, median (IQR) } \\
\hline RFA & $3.0(3.0,3.0)$ & $2.0(1.0,2.0)^{\star *}$ & $2.0(1.0,2.0)^{\star \star}$ & $1.0(1.0,2.0)^{\star \star}$ \\
\hline BEC & $3.0(2.0,3.0)$ & $2.0(1.0,2.0)^{\star *}$ & $1.0(1.0,1.0)^{\star *}$ & $1.0(1.0,1.0)^{\star *}$ \\
\hline$p$-value & 0.428 & 1.000 & 0.109 & 0.134 \\
\hline \multicolumn{5}{|c|}{ ESS, median (IQR) } \\
\hline RFA & $10.0(7.5,13.8)$ & $6.5(3.5,7.0)^{*}$ & $6.0(3.5,6.5)^{\star *}$ & $5.0(3.0,7.5)^{\star}$ \\
\hline BEC & $9.5(7.2,13.0)$ & $8.5(4.4,9.8)$ & $6.0(3.0,9.0)$ & $5.5(3.2,7.0)^{\star}$ \\
\hline p-value & 0.854 & 0.239 & 0.559 & 0.732 \\
\hline \multicolumn{5}{|c|}{ Total FOSQ, median (IQR) } \\
\hline RFA & $89.0(56.2,95.2)$ & $102.0(88.5,111.8)$ & $101.0(73.0,105.0)$ & $96.5(78.2,102.0)$ \\
\hline BEC & $84.5(80.5,101.8)$ & $85.5(71.5,109.5)$ & $95(91.0,106.0)$ & $96.5(88.0,102.0)$ \\
\hline p-value & 0.679 & 0.290 & 1.000 & 1.000 \\
\hline
\end{tabular}

${ }^{*} \mathrm{p}$-value (pre-post-treatment) $<0.05,{ }^{* *} \mathrm{p}$-value (pre-post-treatment) $<0.001$

S.D.=standard deviation, IQR=interquartile range, RFA=radiofrequency ablation, BEC=bipolar electrocautery, PNIF=peak nasal inspiratory flow, ESS=Epworth sleepiness scale, FOSQ=functional outcome of sleep questionnaire 
Table 4 Comparison of the compliance, attitude and ease of use of continuous positive airway pressure at baseline, 1, 3 and 6 months after treatment

\begin{tabular}{lllll}
\hline Parameters & Pre-treatment & 1 month & 3 months & 6 months \\
\hline CPAP compliance, mean (S.D.) & & & & \\
RFA & $81.4(21.7)$ & $92.6(8.1)$ & $82.9(24.0)$ & $88.9(15.3)$ \\
BEC & $66.6(29.2)$ & $80.1(29.8)$ & $87.1(24.0)^{*}$ & $88.4(18.2)^{*}$ \\
P-value & 0.140 & 0.143 & 0.646 & 0.938 \\
CPAP attitude, mean (S.D.) & & & \\
RFA & $1.7(2.8)$ & $1.4(2.3)$ & $1.0(1.3)$ & $0.5(0.9)$ \\
BEC & $3.4(4.0)$ & $2.9(2.7)$ & $1.4(2.3)$ & $1.1(1.8)^{*}$ \\
P-value & 0.205 & 0.150 & 0.542 & 0.271 \\
Ease to use, mean (S.D.) & & & & $0.9(1.3)^{*}$ \\
RFA & $2.4(2.6)$ & $2.0(2.3)$ & $1.5(1.9)$ & $0.6(1.1)$ \\
BEC & $2.0(2.7)$ & $1.7(2.2)$ & $0.9(1.1)$ & 0.518 \\
P-value & 0.693 & 0.752 & 0.309 & \\
\hline
\end{tabular}

${ }^{*} \mathrm{p}$-value (pre-post-treatment) $<0.05$

S.D.=standard deviation, $\mathrm{CPAP}=$ continuous positive airway pressure, RFA=radiofrequency ablation, $\mathrm{BEC}=$ bipolar electrocautery

In the BEC group, there was a significant improvement in the CPAP compliance at 3 and 6 months. In contrast, the compliance did not change in the RFA group at before and six months postoperation. There were no statistically significant differences in the attitude and ease of CPAP use at 1 and 3 months in both groups. However, at 6 months postoperation, the attitude significantly improved in BEC ( $p$-value $=0.046)$ and the ease of use was better in the RFA group ( $p-v a l u e=$ 0.047) (Table 4). Regarding immediate postoperative pain, the scores were higher in the RFA group than in the BEC group. The 2-week pain scores decreased without a significant difference between the groups. Moreover, the rescue medication was taken without differences as well. There were no complications in either group.

\section{Discussion}

Although CPAP is currently a highly effective treatment for OSA, patient compliance is not satisfactory and remains a difficult issue. Approximately half of the patients had not accepted it or had abandoned its use. ${ }^{27}$ Moreover, up to two-thirds of the OSA patients did not use a CPAP machine in the long-term follow-up. ${ }^{28}$ Nasal obstruction is the main symptom complained about during CPAP therapy. It is typically caused by inferior turbinate hypertrophy and eventually leads to CPAP intolerance. In this study, we assessed nasal obstruction both preoperatively and postoperatively at 1, 3 and 6 months. Both the BEC and RFA groups exhibited significant decreases in nasal obstruction at 1, 3 and 6 months postoperation; however, there is not different between the two groups. At 6 months postoperation, this symptom improved by $83.4 \%$ in the RFA group compared with $64.2 \%$ in the BEC group. Our results are consistent with those of a previous study that reported $80.0 \%-100.0 \%{ }^{29,30}$ and approximately $90.0 \%$ were able to stop medications for nasal obstruction after RFA treatment. ${ }^{31-39}$ In contrast, Kilavuz et al. ${ }^{40}$ showed that the BEC was more effective than the RFA at 8 weeks postoperation; however, the previous study used an electrocautery energy twice as high as that in our study. Moreover, the total nasal symptoms decreased in both groups at 1, 3 and 6 months. At 6 months postoperation, the symptoms improved significantly by $75.7 \%$ and $40.6 \%$ in the RFA and BEC groups, respectively. In this 
study, the reduction in other nasal symptoms, including rhinorrhoea, sneezing, coughing, itchy nose and postnasal drip, were found more in the RFA group than in the BEC group, as in a previous study by Banhiran et al. ${ }^{38}$ This might be explained by the energy which ablated the nerves and ceruminous glands.

In both groups, the inferior turbinate was significantly reduced in size, and the nasal airflow improved at 6 months postoperation. Interestingly, the CPAP compliance obviously improved in the BEC group after 3 months post-surgery. Contrarily, in the RFA group, the CPAP compliance did not significantly change. This could be explained by the fact that the baseline compliance was higher in the RFA group. Nevertheless, there were many factors that could have interfered in the use of CPAP, such as the use of a high CPAP pressure, dry throat, mask phobia, discomfort of equipment or poor attitude. However, in this study, the attitude towards and ease of CPAP were rather good at before and after treatment in both groups. Since the patients received more CPAP usage, their daytime sleepiness evaluation via ESS was significantly improved at 6 months postoperation in both groups. In addition, the scores of FOSQ tended to improve in both groups. In contrast, a study on the overall quality of life in patients with chronic rhinitis, refractory to medication and who underwent inferior turbinate reduction, revealed a significant improvement in all dimensions by the $8^{\text {th }}$ week after RFA treatment. ${ }^{38}$

The previous study showed that postoperative pain was lower with the RFA because of the lower energy. In contrast, our study showed no differences in the postoperative pain between the RFA and BEC groups. Both surgical techniques were minimally invasive under local anaesthesia, with mild postoperative pain and no serious complications. Their mechanisms involved forming a scar in the submucosal layer of the inferior turbinate without damaging the mucociliary function.
The advantage of this study is that the surgical procedures were performed by a single otolaryngologist. The skill of the physician seems to play a dominant role in the surgical outcome. Moreover, there have not yet been any studies comparing both surgical techniques in OSA patients using CPAP therapy. The limitation of the present study is that it was a short-term study with a small sample size. To improve this limitation, the authors will continue to follow the participants in the long term to evaluate the recurrence of nasal symptoms and its relationship with CPAP compliance. However, the present study confirmed that the effectiveness of both techniques was similar and satisfied the relief of nasal obstruction, improvement of CPAP compliance, and decrease of daytime sleepiness. Nowadays, electrocautery equipment is a basic inexpensive instrument that is more widely used in many hospitals than the radiofrequency equipment. Thus, it can be used as an alternative option in the treatment of nasal obstruction, especially in OSA patients using CPAP.

\section{Conclusion}

Both RFA and BEC have the ability to relieve nasal obstruction in OSA patients who use CPAP, which help improve CPAP compliance and relieve daytime sleepiness.

\section{Acknowledgement}

The authors would like to thank the Faculty of Medicine, Prince of Songkla University for funding and Miss Nannapat Pruphetkaew for her assistant in data analysis.

\section{Funding sources}

This work was supported by the Medical Research Council (grant number 59-195-13-1) 


\section{Conflict of interest}

None declared

\section{References}

1. Young T, Palta M, Dempsey J, Skatrud J, Weber S, Badr S. The occurrence of sleep-disordered breathing among middle-aged adults. N Engl J Med 1993;328:1230-5.

2. Neruntarat C, Chantapant S. Prevalence of sleep apnea in HRH Princess Maha Chakri Sirinthorn Medical Center, Thailand. Sleep Breath 2011;15:641-8.

3. Terran-Santos J, Jimenez-Gomez A, Cordero-Guevara J. The association between sleep apnea and the risk of traffic accidents. N Engl J Med 1999;340:847-51.

4. Martin JM, Carrizo SJ, Vicente E, Agusti GA. Long-term cardiovascular outcomes in men with obstructive sleep apnoea-hypopnoea with or without treatment with continuous positive airway pressure: an observational study. Lancet 2005;365:1046-53.

5. Yaggi HK, Concato J, Kernan WN, Lichtman JH, Brass LM, Mohsenin V. Obstructive sleep apnea as a risk factor for stroke and death. N Engl J Med 2005;353:2034-41.

6. Marshall NS, Wong KK, Liu PY, Cullen SR, Knuiman MW, Grunstein RR. Sleep apnea as an independent risk factor for all-cause mortality: the Busselton Health Study. Sleep 2008;31:1079-85.

7. Young T, Finn L, Peppard PE, Szklo-Coxe M, Austin D, Nieto FJ, et al. Sleep disordered breathing and mortality: eighteenyear follow-up of the wisconsin sleep cohort. Sleep 2008;31: 1071-8.

8. Kushida CA, Littner MR, Hirshkowitz M, Morgenthaler MI, Alessi CA, Bailey D, et al. Practice parameters for the use of continuous and bilevel positive airway pressure devices to treat adult patients with sleep-related breathing disorders. Sleep 2006;29:375-80.

9. Giles TL, Lasserson TJ, Smith BJ, White J, Wright J, Cates CJ. Continuous positive airways pressure for obstructive sleep apnoea in adults. Cochrane Database Syst Rev 2006;1:1-15.

10. Staevska MT, Mandajieva MA, Dimitrov VD. Rhinitis and sleep apnea. Curr Allergy Asthma Rep 2004;4:193-9

11. Li H, Engleman H, Hsu C, Izci B, Vennelle M, Cross M, et al. Acoustic reflection for nasal airway measurement in patients with obstructive sleep apnea-hypopnea syndrome. Sleep 2005;28:1554-9.

12. Egan KK, Kezirian EJ, Kim DW. Nasal obstruction and sleep disordered breathing. Oper Tech Otolayngol 2006;17:268-72.

13. Janson C, Noges E, Svedberg-Brandt S, Linberg E. What characterizes patients who are unable to tolerate continuous positive airway pressure (cpap) treatment?. Resp Med 2000; 94:145-9.

14. Zozula R, Rosen R. Compliance with continuous positive airway pressure therapy: assessing and improving treatment outcomes. Curr Opin Pulm Med 2001;7:391-8.

15. Mickelson SA. Medical management and definition of continuous positive airway pressure failure. Oper Tech Otolaryngol Head Neck Surg 2006;17:216-22.

16. Mador MJ, Krauza M, Pervez A, Pierce D, Braun M. Effect of heated humidification on compliance and quality of life in patients with sleep apnea using nasal continuous positive airway pressure. Chest 2005;128:2151-8

17. Martins De Araujo MT, Vieira SB, Vasquez EC, Fleury B. Heated humidification or face mask to prevent upper airway dryness during continuous positive airway pressure therapy. Chest 2000;117:142-7.

18. Winck JC, Delgado JL, Almeida JM, Marques JA. Heated humidification during nasal continuous positive airway pressure for obstructive sleep apnea syndrome: objective evaluation of efficacy with nasal peak inspiratory flow measurements. Am J Rhinol 2002;16:175-7.

19. Charakorn N, Hirunwiwatkul P, Chirakalwasan N, Chaitusaney B, Prakassajjatham M. The effects of topical nasal steroids on continuous positive airway pressure compliance in patients with obstructive sleep apnea: a systematic review and metaanalysis. Sleep Breath 2017;21:3-8.

20. Camacho M, Riaz M, Capasso R, Ruoff CM, Guilleminault C, Kushida CA. The effect of nasal surgery on continuous positive airway pressure device use and therapeutic treatment pressures: a systemic review and meta-analysis. Sleep 2015; 38:279-86.

21. Sufioglu M, Ozmen OA, Kasapoglu F, Demir UL, Ursavas A, Erisen L, et al. The efficacy of nasal surgery in obstructive sleep apnea syndrome: a prospective clinical study. Eur Arch Otorhinolaryngol 2012;269:487-94.

22. Aurora RN, Casey KR, Kristo D, Auerbach S, Bista SR, 
Chowdhuri S, et al. Practice parameters for the surgical modifications of the upper airway for obstructive sleep apnea in adults. Sleep 2010;33:1408-13.

23. Powell NB, Zonato Al, Weaver EM, Li K, Troell R, Riley RW. Radiofrequency treatment of turbinate hypertrophy in subjects using continuous positive airway pressure: a randomized, double-blind, placebo-controlled clinical pilot trial. Laryngoscope 2001;111:1783-90.

24. Friedman M, Tanyeri H, Lim J, Landsberg R, Caldarelli D. A safe, alternative technique for inferior turbinate reduction. Laryngoscope 1999;109:1834-7.

25. Banhiran W, Assanasen P, Nopmaneejumruslers C, Metheetrairut C. Epworth sleepiness scale disordered breathing: the reliability and validity of the Thai version. Sleep Breath 2011;15: 571-7.

26. Banhiran W, Assanasen P, Metheetrairut C, Nopmaneejumruslers C, Chotinaiwattarakul W, Kerdnoppakhun J. Functional outcomes of sleep in thai patients with obstructive sleep-disordered breathing. Sleep Breath 2012;16:663-75.

27. Wolkove N, Baltzan M, Kamel H, Dabrusin R, Palayew M. Long-term compliance with continuous positive airway pressure in patients with obstructive sleep apnea. Can Respir J 2008;15: 365-9.

28. Sarrell EM, Chomsky O, Shechter D. Treatment compliance with continuous positive airway pressure device among adults with obstructive sleep apnea (OSA): how many adhere to treatment? Harefuah 2013;152:140-4.

29. Fischer Y, Gosepath J, Amedee RG, Mann WJ. Radiofrequency volumetric tissue reduction (RFVTR) of inferior turbinates: a new method in the treatment of chronic nasal obstruction. Am J Rhinol 2000;14:355-60.

30. Porter MW, Hales NW, Nease CJ, Krempl GA. Long-term results of inferior turbinate hypertrophy with radiofrequency treatment: a new standard of care? Laryngoscope 2006;116:554-7.

31. Saulescu M, Sarafoleanu C. Surgery for nasal obstruction in inferior turbinate hypertrophy. Romanian Journal of Rhinology 2015;5:25-30
32. Garzaro M, Pezzoli M, Landolfo V, Defilippi S, Giordano C, Pecorari G. Radiofrequency inferior turbinate reduction: longterm olfactory and functional outcomes. Otolaryngol Head Neck Surg 2012;146:146-50.

33. Hirunwiwatkul P, Aeumjaturapata $S$, Oraphin P. Results of temperature-controlled radiofrequency tissue volume reduction for the turbinate hypertrophy. J Med Assoc Thai 2004; 87(Suppl 2):S91-4.

34. Nease CJ, Krempl GA. Radiofrequency treatment of turbinate hypertrophy: a randomized, blinded, placebo-controlled clinical trial. Otolaryngol Head Neck Surg 2004;130:291-9.

35. Cavaliere M, Mottola G, Lemma M. Comparison of the effectiveness and safety of radiofrequency turbinoplasty and traditional surgical technique in treatment of inferior turbinate hypertrophy. Otolaryngol Head Neck Surg 2005;133: 972-8.

36. Utley DS, Goode RL, Hakim I. Radiofrequency energy tissue ablation for the treatment of nasal obstruction secondary to turbinate hypertrophy. Laryngoscope 1999;109:683-6.

37. Shah AN, Brewster D, Mitzen K, Mullin D. Radiofrequency coblation versus intramural bipolar cautery for the treatment of inferior turbinate hypertrophy. Ann Oto Rhinol Laryngol 2015; 124:691-7.

38. Uluyol S, Karakaya NE, Gur MH, Kilicaslan S, Kantarcioglu $E O$, Yagiz $O$, et al. Radiofrequency thermal ablation versus bipolar electrocautery for the treatment of inferior turbinate hypertrophy: comparison of efficacy and postoperative morbidity. Int Arch Otolarhinolaryngol 2016;20:2-5.

39. Banhiran W, Tantilipikorn P, Metheetrairut C, Assanasen P, Bunnag C. Quality of life in patients with chronic rhinitis after radiofrequency inferior turbinate reduction. J Med Assoc Thai 2010;93:950-60.

40. Kilavuz AE, Songu M, Ozkul $\mathrm{Y}$, Ozturkcan S, Katilmis H. Radiofrequency versus electrocautery for inferior turbinate hypertrophy. J Craniofac Surg 2014;26:1998-2001. 